\title{
Trophic plasticity of Antarctic echinoids under contrasted environmental conditions
}

\author{
Michel Loïc', Bruno David², Philippe Dubois³, Gilles Lepoint ${ }^{1}$ and Chantal De Ridder ${ }^{3}$ \\ 1 Laboratory of Oceanology, MARE Centre, University of Liege, Liege, Belgium, B6c, Quartier Agora, \\ Allée du 6 Août 11, 4000 Liège, Belgium \\ E-mail: loicnmichel@gmail.com \\ 2 Biogéosciences, UMR CNRS 6282, Université de Bourgogne, Dijon, France, \\ 3 Laboratoire de Biologie Marine, Université Libre de Bruxelles, Brussels, Belgium
}

Echinoids are common members of Antarctic zoobenthos, and different groups can show important trophic diversity. As part of the ANT-XXIX/3 cruise of RV Polarstern, trophic plasticity of sea urchins was studied in three neighbouring regions (Drake Passage, Bransfield Strait and Weddell Sea) featuring several depth-related habitats offering different trophic environments to benthic consumers. Three families with contrasting feeding habits (Cidaridae, Echinidae and Schizasteridae) were studied. Gut content examination and stable isotopes ratios of $\mathrm{C}$ and $\mathrm{N}$ suggest that each of the studied families showed a different response to variation in environmental and food conditions. Schizasteridae trophic plasticity was low, and these sea urchins were bulk sediment feeders relying on sediment-associated organic matter in all regions and/or depth-related habitats. Cidaridae consumed the most animalderived material. Their diet varied according to the considered area, as sea urchins from Bransfield Strait relied mostly on living and/or dead animal material, while specimens from Weddell Sea fed on a mixture of dead animal material and other detritus. Echinidae also showed important trophic plasticity. They fed on various detrital items in Bransfield Strait, and selectivity of ingested material varied across depth-related habitats. In Weddell Sea, stable isotopes revealed that they mostly relied on highly ${ }^{13} \mathrm{C}$ enriched food items, presumably microbially-reworked benthic detritus. The differences in adaptive strategies could lead to family-specific responses of Antarctic echinoids to environmental and foodrelated changes.

Keywords: Antarctic; echinoids; feeding behaviour; stable isotopes; ecological plasticity; diet shift 